\title{
Prophylactic use of LMWH plus intermittent pneumatic compression prevented DVT in hip or knee arthroplasty
}

Silbersack Y, Taute BM, Hein W, et al. Prevention of deep-vein thrombosis after total hip and knee replacement. Low-molecular-weight heparin in combination with intermittent pneumatic compression. J Bone Joint Surg Br 2004;86:809-12.

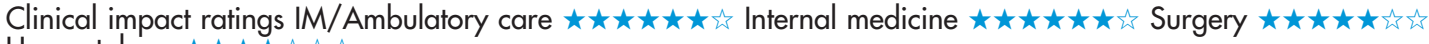

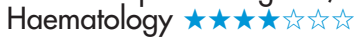

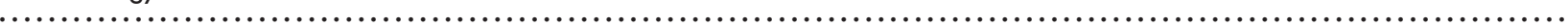

In patients receiving primary unilateral total hip or total knee replacement surgery, is prophylactic use of low molecular weight heparin (LMWH) plus intermittent pneumatic compression more effective than LMWH plus graduated compression stockings for reducing deep venous thrombosis (DVT)?

\section{METHODS}

L

Design: randomised controlled trial.

$\triangle$

Allocation: $\left\{\right.$ concealed $\left.^{*}\right\}$

(-)

Blinding: unblinded.*

$\sum<$

Follow up period: 6-12 weeks

Setting: a university hospital in Germany

Patients: 139 patients $\geqslant 18$ years of age who were awaiting primary unilateral total hip or knee replacement. Exclusion criteria included a history of cardiac insufficiency and chronic renal insufficiency.

$\mathbb{R}_{\mathbf{x}}$

Intervention: thromboembolic prophylaxis with $\mathrm{LMWH}$ plus intermittent pneumatic compression $(n=70)$ or $L M W H$ plus graduated compression stockings (class $1,20-30 \mathrm{~mm} \mathrm{Hg}$ ) $(n=69)$ after surgery. LMWH prophylaxis comprised anti-Xa enoxaparin-natrium, $4000 \mathrm{IU}$ per day. Intermittent pneumatic compression using a Venaflow System with 2 cell calf cuffs commenced directly after surgery in the recovery room and continued for 10 days. After intermittent pneumatic compression, patients were fitted with graduated compression stockings on both legs. Patients without thromboembolic complication continued LMWH prophylaxis for 30 days and wore graduated compression stockings for $\leqslant 3$ months.

Outcomes: DVT at day 6-12 (diagnosed by compression ultrasonography).

Patient follow up: $94 \%$ (mean age $64 \mathrm{y}, 64 \% \mathrm{men}$ ).

* See glossary.

tInformation provided by author

For correspondence. Dr Y Silbersack, Martin Luther University, Halle/Salle Germany

Source of funding: Aircast Europa $\mathrm{GmbH}$

\section{MAIN RESULTS}

The table shows the results. $\{5$ of the 18 patients with DVT were symptomatic. $\}^{*}$

\section{CONCLUSION}

In patients who have total hip or total knee replacement, prophylactic use of low molecular weight heparin (LMWH) plus intermittent pneumatic compression was more effective than LMWH plus graduated compression stockings for preventing deep venous thrombosis.

*Information provided by author.

\section{Commentary}

ombining mechanical with pharmacological methods of thromboprophylaxis in patients who have total hip or knee replacement is attractive because these patients have a $1-3 \%$ incidence of inhospital symptomatic DVT and a 15-30\% prevalence of asymptomatic DVT at hospital discharge despite routine LMWH or warfarin. ${ }^{1}$ Few studies have evaluated the effectiveness of combined thromboprophylaxis or compared the effectiveness of different mechanical methods in major orthopaedic surgery. ${ }^{2} 3$

The study by Silbersack et al showed a $100 \%$ (95\% Cl $81 \%$ to $100 \%$ ) relative risk reduction of DVT in high risk patients who received LMWH plus intermittent pneumatic compression compared with those who received LMWH plus graduated compression stockings. DVT did not occur in any of the 70 patients randomised to intermittent pneumatic compression despite premature discontinuation of treatment in almost $26 \%$ of patients $(18 / 70)$ in this group. These promising results suggest a wider role for combined intermittent pneumatic compression and LMWH in patients who have total hip or knee replacement.

However, important issues remain unresolved. Firstly, all but 2 of the 18 outcome events in this trial were distal thrombi. Prevention of these events is of limited clinical relevance because most resolve spontaneously and only about one sixth extend to involve the proximal veins. ${ }^{4}$ Secondly, a significant reduction in proximal or symptomatic thrombi (which are clinically most important) was not shown; the study was not powered for these outcomes. Thirdly, outside of a clinical trial setting, compliance with IPC is likely to be even lower than observed in this study. This drawback may reduce the effectiveness of IPC in routine clinical practice. Future studies should address these issues.

John W Eikelboom, MD McMaster University Hamilton Ontario Canada

1 Geerts WH, Pineo GF, Heit JA et al. Chest 2004:126:338S-400S.

2 Vanek VW. Am Surg 1998;64:1050-8.

3 Amaragiri SV, Lees TA. Cochrane Database Syst Rev 2000;(3):CD001 484.

4 Kearon C Circulation 2003;107:122-30.

Prophylactic use of low molecular weight heparin (LMWH) plus intermittent pneumatic compression (IPC) $v$ LMWH plus graduated compression stockings (GCS) in unilateral hip or knee arthroplasty*

\begin{tabular}{lllll}
\hline Outcomes at 12 days & LMWH/IPC & LMWH/GCS & RRR (95\% CI) & NNT (CI) \\
\hline Patients with deep venous thrombosis & $0 \%$ & $29 \%$ & $100 \%$ (81 to 100) & 4 (3 to 6) \\
\hline *Abbreviations defined in glossary; RRR, NNT, and Cl calculated from data in article. & &
\end{tabular}

